of I cents a mile to overseas visitors for the transcontinental excursion, exclusive of sleeping berths. The exact route has not yet been decided, but an approximate estimate of the expenses is $I 7 l$. for fare and $I_{5} l$. for berths, and the total cost of the excursion will be, approximately, $50 l$.

The officers of the local committee dealing with arrangements in Toronto are as follows: Chairman of general and executive committees: Prof. J. C. McLennan; local hon. secretaries: Prof. J. C.
Fields, University, Toronto, and Prof. J. J. R. MacLeod, University, Toronto; assistant local secretary: Major J. M. Mood; local hon. treasurer: Dr. F. A. Mouré, University of Toronto.

Delegates of Corresponding Societies will meet, by invitation of the Museums Association, during the meeting organised by that Association at the British Empire Exhibition, Wembley, on July 2I-26. At the British Association meeting, there will be a conference of local scientific societies.

\title{
The Tarnishing and Fogging of Metals.
}

\author{
By Prof. H. C. H. Carpenter, F.R.S.
}

SOME years ago, as a result of the action taken by certain members of the Royal Institute of British Architects, a Committee was set up composed of representatives of that Institute, the Institute of Metals, and the British Non-Ferrous Metals Research Association, charged with the duty of making arrangements for the experimental investigation of the causes of the atmospheric corrosion of non-ferrous metals. The necessary funds were provided by the Department of Scientific and Industrial Research, the British Non-Ferrous Metals Research Association, and various interested persons. Mr. W. H. J. Vernon was appointed to carry out the experimental work, and the report of his first investigation was presented and discussed at the Faraday Society on December $x>$ last.

The research has been initiated and developed mainly along two lines: (I) Tests carried out with relatively large specimens exposed to representative atmospheres in order to compare their effects on typical metals and alloys, and to correlate the behaviour of as wide a range of materials as possible; and (2) laboratory experiments conducted on relatively small specimens with the object of obtaining insight into the mechanism of tarnishing and corrosion. The present report deals mainly with tarnishing, filming, and fogging, which represent the early stages of corrosion. Four types of atmosphere were investigated: (I) An indoor atmosphere maintained continuously in the unsatuıated condition with respect to water vapour; (2) an indoor atmosphere of variable but relatively high humidity, occasionally reaching saturation; (3) an ordinary domestic kitchen: and (4) open-air exposure on the roof of the Royal School of Mines building at South Kensington. The specimens have been examined visually and with the aid of a microscope, accurate determinations have been made of the increase in weight of the test-pieces from time to time; but probably the method which has given the most information has been an optical one, in which, after suitable preparation, the reflectivities of the surfaces have been determined, both in the freshly cleaned condition and during the course of exposure. Mr. Vernon has found that the loss of reflectivity affords a very sensitive means of estimating the changes taking place at the surface, more particularly in the earliest stages of tarnishing. His method consisted in comparing the light from two similar lamps in a Lummer Brodhun photometer, one of the lamps being so arranged that its light could be either (I) allowed to fall directly upon the photometer, or (2) reflected on to it from the metal surface under examination, the total length of the beam being the same in each case. The use of a suitable colour screen placed over the eye-piece of the photometer was necessary.

Three types of curves, the co-ordinates of which are weight-increment and time, have been obtained and their significance discussed in relation to the function of the tarnishing product or scale obtained.
In the first case, the curve is a parabola the axis of which coincides with the time axis of the co-ordinates. Weight-increment is thus proportional to the square root of the time; that is, the rate of attack is retarded as the period of exposure increases. The scale forms a continuous envelope and subsequent tarnishing can only take place by diffusion of the corroding atmosphere through it. From the point of view of the solution of the problems envisaged by the Committee this is the most favourable case. Copper within a wide range of humidity variations falls within this class. In the second case, the curve is a straight line passing through the origin, and weightincrement is directly proportional to the time. Here the scale is completely permeable and allows free access of the atmosphere to the metal. A typical example is furnished by zinc in an unsaturated atmosphere. In the third case, the curve is a parabola the axis of which coincides with the weight axis. Weightincrement is proportional to the square of the time; that is, the rate of attack is accelerated as the period of exposure increases. The scale is not merely permeable but discontinuous. The metal iron in an atmosphere of relatively high humidity corrodes in this way. The influence of the condition of the surface has been carefully examined, and, as a rule, the rougher it is the greater the tendency to tarnish.

At least two, if not three, types of attack have been found to take place. There is, first of all, what Mr. Vernon terms " tarnishing," in which characteristic colour changes are brought about by the presence of gaseous sulphur compounds. Liquid water is not necessary, for the action takes place at temperatures considerably above the dew-point and increases as the temperature is raised. Excess of water vapour reduces the rate of tarnishing. The presence of either solid or liquid particles appears to be without appreciable influence. The metal copper furnishes a variety of instances of tarnishing according to the condition of the atmosphere.

Another variety of attack is the " smoky" film, developed in an unsaturated polluted atmosphere on the high zinc brasses. Microscopical examination shows that in the early stages the action predominates on the a (copper rich) constituent, while subsequently within the areas occupied by the "smoky" film the attack is largely concentrated upon the $\beta$ (zinc rich) constituent. This attack appears to be due to the presence of solid or liquid particles, probably sulphuric acid. A third type of attack is illustrated by the behaviour of nickel in an indoor atmosphere at temperatures near to the dew-point, when a characteristic filming or fogging of the surface occurs. This film may readily be removed in the early stages but becomes more persistent as the duration of exposure increases. The same phenomenon is shown by nickel-copper alloys. In such cases a humid atmosphere produces " fog " and an unsaturated atmosphere gives rise to tarnish.

NO. 283 I, VOL. I I 3 ] 
It is to be hoped that Mr. Vernon will develop his research on the lines of investigating the phenomena of tarnishing, filming, and fogging with the view of finding out exactly what they really are. They undoubtedly represent the early stages of corrosion, and if they can be prevented from taking place, atmospheric corrosion will seldom, if ever, occur. Their elucidation will require strictly controlled laboratory experiments where the effect of each variable can be determined.

\section{Scientific Societies in Poland.}

THE following short account of some of the scientific societies recently organised or reorganised in Poland will be of interest to scientific workers.

The Polish Chemical Society, established in I9I9, has at the present time five local branch sections (Warsaw, Cracow, Lwow, Poznan, Lodz) and 539 members. Its chief publication is the Roczniki Chemii (Annals of Chemistry), appearing in yearly volumes of about 600 pages each. The address of the Society's Office is: High Technical College (Politechnika), 75 Koszykowa, Warsaw. In I9I9 a National Chemical Council was founded, consisting of representatives of pure and applied chemistry, under the presidency ex officio of the State Minister of Commerce and Industry. This advisory body directs the policy of the State in matters respecting chemical industry in time of peace and war.

The Polish Mathematical Society, founded in Cracow in rgrg and reorganised in I920, under the presidency of Prof. W. Staniewicz, has two local sections (Cracow, Lwow), and publishes proceedings under the title: Annales de la Société Mathématique Polonaise.

The Polish Radiotechnical Association, founded in Warsaw in $\mathrm{rg22}$, has affiliated branch sections in Poznan, Torun, Lwow; the president is Commander Jackowski.

The Polytechnic Society of Warsaw, initiated in I9I8, reorganised in I92I, publishes Proceedings at regular intervals; the president is Prof. $\mathrm{H}$. Czopowski, of the Warsaw High Technical Coliege.

The Polish Botanical Society edits (i.) Acta Societatis Botanicorum Poloniæ, (ii.) Przeglad Botaniczny (abstracts of current botanical literature). The Society is under the presidency of Prof. B. Hryniewiecki (6/8 Aleja Ujazdowska, Warsaw).

The Polish Ethnological Society, originated in 1921 in Warsaw, under the leadership of Prof. Jan Czekanowski; it publishes the quarterly review $L u d$ and the collection entitled Wisla. The Wisla series is a continuation of a valuable collection published by the late Prof. Majewski (20 volumes). The last volume of Wisla is devoted to Dr. Ciszewski's elaborate paper "Common Salt."

The Copernicus Association of Polish Naturalists, fpunded in 1874 in Lwow, was reconstituted in I9I8. Its chief publication is the monthly periodical Kosmos; forty-six yearly volumes have already appeared. The papers printed in Kosmos are written in Polish, with substantial résumés in French, English, or German. The collection of geological papers contained in the Kosmos series is of exceptional value and importance for the geology of Poland. The total membership of the Association is $45 \mathrm{I}$. To promote the diffusion of natural knowledge in Poland, the Association publishes a separate monthly magazine of popular character. A limnological station was established in I9II, under the auspices of the Association, in Drozdowice, in the neighbourhood of Grodek Jagiellonski ; destroyed by the Russian Army in 1915, the station was re-erected in I920. Another limnological station exists in Plociczno, about Io $\mathrm{km}$. from Suwalki ; this station, which owes its foundation to the Scientific Society of Warsaw, has now been at work for about three years, under the direction of Dr. Litynski.

In addition, there are the Cracow Academy of Sciences and the Polish Physical Society, references to the activities of which were made in NATURE of July 28 , p. I4O, and August 4, p. I73.

In 1920 , fifteen Polish scientific societies existing in Lwow appointed a Joint Scientific Board with a view of co-ordinating and unifying their efforts. This organisation includes now, under the leadership of the Scientific Society of Lwow, twenty-six societies and institutions existing in Lwow and the Philological Society of Przemysl.

Poland is doing well to encourage by all the means in its power the growth of scientific organisations which tend to provide the highest kind of instruction and to disseminate knowledge.

\section{Soil Sourness.}

THE meeting of the Section of Botany of the British Association at Liverpool concluded with a discussion upon "The Effect of Soil Sourness on Plants," in which the various theories put forward to account for this condition were debated.

The discussion was opened by Mr. A. G. Tansley, who emphasised the extreme complexity of the problem, and the need for ecologists to analyse carefully the soil factor. Having briefly mentioned the chief types of plant communities found on acid soils in Britain, he considered the relation of xerophilous structure to soil sourness, pointing out that Schimper's theory of "physiological dryness" was an inadequate explanation of the correlation. The influence of the hydrogen-ion concentration of the soil upon the distribution was then considered. It was pointed out that the effect of sourness might not be directly due to the hydrogen-ion concentration, but to various causes, such as the presence of soluble toxic salts, the ratios of certain soil bases one to the other, etc.
Dr. E. J. Salisbury emphasised the fact that the incidence of wild species in relation to hydrogen-ion concentration could be presented as a variation curve with a principle mode $\left(e . g . \mathrm{P}_{\mathrm{H}} 5.5\right.$ for Pteridium aquilinum, $\mathrm{P}_{\mathrm{H}} 7 \cdot 2$ for Psamma arenaria, etc.). The range for a given species is often considerable, depending upon other factors of the environment, of which competition and water content were specially cited. For most species the incidence curve exhibits a second mode which is very marked for those the primary mode of which is near the neutral point (e.g. Mercurialis perennis, Ficaria verna, etc.). The correspondence of this bimodal curve with that for growth in culture solutions of varying hydrogen-ion concentration but constant ratio of bases was emphasised. The incidence curves represented the summation of both direct and indirect effects of acidity, but demonstrated the importance of this habitat factor. It was pointed out that the effects of acidity were manifested beyond the point at which toxic iron and aluminium salts are precipitated. It

$$
\text { No. } 283 \text { I, voL. I I } 3 \text { ] }
$$

